\title{
VISIONES SOBRE LAS REDES SOCIALES EN LA CONSTRUCCIÓN DE LA REALIDAD MEDIÁTICA
}

VIEWPOINTS ABOUT SOCIAL NETWORKING IN THE CONSTRUCTION OF MEDIA REALITY

\section{RESUMEN}

Partiendo de una apreciación sobre las redes sociales y la comunicación cotidiana se realiza una aproximación al conocimiento del impacto de las redes sociales sobre la actividad periodística en diversas realidades, basada en la evidencia científica más reciente a nivel internacional.

Palabras clave: Redes sociales - Comunicación cotidiana - Periodismo - Realidad mediática

\section{ABSTRACT}

Starting from an appreciation of social networks and daily communication, an approach is made to the knowledge of the impact of social networks on journalistic activity in different realities, based on the most recent scientific evidence at an international level.

Keywords: social networking - Everyday communication - Journalism - Media reality 


\section{Punto de partida: Las redes y la comunicación cotidiana}

Desde una perspectiva bastante amplia,las redes sociales como modalidades de intercambio social se han conformado desde las primeras épocas de existencia del ser humano. La teoría de las redes sociales estima que en la vida diaria configuramos diversas redes sociales, de características distintas, con diferente grado de importancia. Hoy en día se habla constantemente de redes sociales y se les utiliza cotidianamente en el mundo entero. Pero cabe preguntarnos ¿sabemos lo que implica una red social? En términos sencillos desde el punto de vista de Butts (2008) consiste en un conjunto de entidades (personas, grupos) que tienen alguna relación entre sí.

Actualmente las redes sociales digitales son parte de la vida cotidiana de millones de personas alrededor del mundo y la tendencia es hacia un crecimiento constante. El informe de la plataforma Hootsuite (2017) revelaba que, a enero del 2017, el 37 por ciento de la población mundial era usuario activo de redes sociales y que el 34 por ciento accedía de modo intensivo a través de su teléfono móvil a las redes sociales tales como Facebook, Twitter, Instagram, Youtube, WhatsApp y Flickr, entre otras. Se produjo un hecho marcadamente significativo hacia fines de junio de 2017 cuando, en un planeta con algo más de siete mil millones de personas, Facebook alcanzó a los dos mil millones de suscriptores alrededor del mundo; vale decir, cerca del 30 de la población mundial.

Lorenzo, Alarcón y Gómez (2011), destacan que las redes sociales digitales suponen una innovación motivando a los individuos a convertirse en productores y creadores de contenidos. A este respecto cabe referirse al concepto de prosumidor que fuera acuñado por Alvin Toffler (1980) y al más reciente de produsuario (Bruns, 2008).

Para utilizar las redes se requiere el aprendizaje progresivo del uso dela tecnología, con una amalgama de instrumentos que permiten navegar en espacios sociales donde se informan y expresan opiniones sobre del acontecer diario. En consonancia con esto, de acuerdo con Chung y Buhalis (2008), las motivaciones de los usuarios se hacen evidentes en tanto se orientan hacia la búsqueda de información con la meta de permanecer actualizados y a su participación, dependiendo de su entorno cultural y la experiencia acumulada en el uso de las redes

La aparición de estas formas de comunicación genera nuevas modalidades de socialización en las cuales se valoran altamente. Su identificación con el medio, adquirida al buscar beneficios informativos y sociopsicológicos, se refuerza en base a lazos de afinidad y espacios de comunidad en red. El contacto digital continuo entre personas afianza lazos de empatía a partir de la imagen del interlocutor que se obtiene en la red. Como señala Quiroz (2014), la red genera la necesidad de interconectarse permanentemente involucrando relaciones donde la comunicación virtual incrementa las posibilidades de la comunicación interpersonal.

\section{Las redes y los medios}

A pesar de un cierto escepticismo inicial sobre su aplicabilidad, en la medida que las redes sociales fueron desarrollando sus recursos, se incorporadas paulatinamente, de diversa manera, en las rutinas de los medios de comunicación.

En la actualidad, cabe reiterar un punto de vista formulado hace solo seis años, el cual señalaba que las redes sociales involucran un desafío para los medios de comunicación, pero también proporcionan nuevas oportunidades (Fowler-Watt and Allan, 2013).

La multiplicidad de plataformas informativas y la multimedialidad posible con la web 2.0 determinan que la información pueda conocerse a través de una serie de recursos de comunicación y con la intervención de diversos agentes, tal como lo destaca Zambrano (2013), entre otros. Para decirlo en palabras de Colle (2016) la característica principal de la información digital es que fluye por múltiples canales. De ahí que hasta la denominada noticia exclusiva casi inmediatamente se viralice y en tiempo real se convierta en información compartida

por decenas de medios y que cruce las fronteras sin necesidad de pasaporte alguno.

Para gestionar el uso de las redes, como 
indican Masip y otros (2010), se parte de las tres características de los medios digitales que tipifican a la web 2.0: La interactividad, la hipertextualidad y la multimedialidad.

En la práctica, Twitter es la plataformamás empleada por los periodistas de distintos países para transmitir sus informaciones periodísticas, debido a que esta red social se desenvuelve más en un contexto profesional que personal. En esta red social solo se permite redactar 140 caracteres por mensaje. Si un periodista es testigo de alguna noticia, lo normal es que la comparta con un tweet que puede, incluso, contener imágenes sobre el acontecimiento. Como indica Pérez (2011), Twitter propaga con facilidad más rumores, pero también permite detectar mentiras más rápido. Los medios deben aprovecharlo para ser más precisos.

En cuanto a Facebook, si bien cuenta con todos los instrumentos requeridos para hacer un buen periodismo digital, dado que se puede redactar sin un límite de caracteres, instalar hipertextos, colocar audios y videos, no es realidad una plataforma periodística como sí lo es Twitter. Esta red se desarrolla dentro de un contexto más personal que profesional, prevalece el contacto entre amigos y, los contenidos compartidos no están relacionados directamente con informaciones periodísticas. El potencial de Facebook para los periodistas radica en la viralidad de la red y en la comunidad de lectores que se pueden crear allí. Los usuarios generan contenido propio de carácter multimedia, lo editan, reenvían, comentan y conversan.

Jesús Flores desarrolla el concepto de isomorfosis entendiéndolo como "el proceso de cambio que están teniendo los mensajes informativos" (Flores, 2009, p.78). Afirma que la tecnología de las redes sociales ejerce influencia tanto en las formas del periodismo como en sus contenidos. El newsmaking, esto es el proceso de construcción de las noticias, ha experimentado notables modificaciones a partir de la aparición y desarrollo de las redes sociales. Inicialmente se les mencionaba de modo limitado, pero en la actualidad los medios impresos los usan para auscultar a la opinión pública mientras que la televisión muestracotidianamentecontenidosgenerados por los usuarios, llegando a presentar en algunos casos una secuencia completa de los mismos. En el caso del atentado de Boston, por ejemplo, las pantallas de las televisoras mostraban inicialmente las imágenes y los videos tomados por los teléfonos móviles de personas quienes pasaban por el lugar.

Un criterio que se enseña desde loscursos introductorios al periodismo es que la información noticiosa se intenta comunicar sobre un hecho de modo directo y asequible al lector directamente y con agilidad. Al respecto, suministrar información en tiempos y espacios cortos es una característica de plataformas como Twitter que inciden en lo esencial, recogiendo habitualmente datos de situaciones en proceso o conclusiones rápidas de hechos importantes o interesantes. Es por ello, que diversos medios dotan a sus periodistas con las versiones más avanzadas de teléfonos inteligentes.

En España los profesionales de los medios de masas demuestran una concepción instrumental altamente reduccionista de las redes. Entre los periodistas, internetcontinúa siendo un elemento disruptor pero, como indica Jaraba (2017), esta disrupciónno se muestra en una actitud de rechazo o enfrentamiento a la novedad sino en una concepción limitada del papel de las redes sociales de internet que no aprovecha sus posibilidades informativas en profundidad.

Las agencias noticiosas internacionales, tradicionales proveedoras de insumos parta los medios consideraron indispensable el uso de las redes sociales y formularon lineamientos para el trabajo con ellas. Desde el 2009, las reconocieron como fuentes informativas y, a partir de ahí, se iniciaron los cambios de roles en los medios.

Bajo el título de "Preguntas y Respuestas sobre redes sociales", a mediados de 2009 la agencia Associated Press (AP) difundió entre sus periodistas un documento que reconocía la importancia que sus empleados tengan presencia en las principales plataformas, indicándose que "se han convertido en una importante herramienta de los periodistas para obtener noticias y buscar fuentes para las historias" (Noguera, 2012, p. 74).

La agencia Reuters, a través de la publicación de su "Handbook Reuters" del 2010, como destacan González-Molina y Ramos del Cano (2014), declaraba a las redes sociales como lugares virtuales se publican 
información e imágenes de gran interés para los clientes de la agencia que no se encuentran en otros lugares y pueden mejorar el trabajo.

El público está condicionando hasta cierto punto los contenidos de los medios, porque dados los recursos que le ofrece la tecnología actual ya no quiere ser solamente lector, espectador u oyente. El público ahora desea interactuar, dejar su opinión y decir a los periodistas lo que a su entender están haciendo bien o mal.

Lo que nos dicen las investigaciones

Es posible formular diversos criteriossobre las implicancias de las redes socialesen el periodismo. Lo más significativo, sin embargo, es lo que nos revela la evidencia científica

Una serie de estudios destacan que las redes cobraron importancia para la labor periodística al facilitar el contactar con fuentes y buscar información (Bunz, 2010; Carrera y otros, 2012a, 2012b; Ramos del Cano, 2013). Esto condujo a varios cambios como la aceleración en la circulación de las noticias (Casero-Ripollés y Feenstra, 2012), el aumento del número de actores participantes en la producción de informaciones (Phillips, 2011).

En la investigación de Thurman (2008) se entrevistaron a editores $y$ funcionarios editoriales de los nueve sitios de noticias más importantes de Gran Bretaña para conocer su visión sobre los cambios en los roles del periodismo y las innovaciones que tienen lugar en las salas de redacción de los medios online. Concordaron en la creciente demanda de la audiencia por espacios para expresar sus puntos de vista. En este sentido, las redes sociales, al convertirse en una herramienta idónea para mantener una comunicación continuada basada en la sencillez, van modificando la relación que se establece entre los medios y el público.

McDonald (2013) realiza un estudio de la industria noticiosa contemporánea, vinculando la interacción entre producción periodística y contenidos generados por los usuarios (CGU). Afirma que es complicado definir el concepto de audiencia. Y que para

la audiencia no está claro cuáles son los contenidos producidos por los profesionales.

El estudio de Gillis y Johnson (2015) demuestra que en general se ha incrementado el uso de las redes sociales entre los periodistas jóvenes quienes utilizan las redes sociales con tres propósitos: Desarrollar ideas para noticias, conectarse con fuentes potenciales y difundir noticias.

Russial, Laufer y Wasko (2005) estimanque se está produciendo un cambio de lógicaen los medios de comunicación en el sentido que la búsqueda de información ya no está centrada en las demandas del medio sino en las expectativas de consumo individualizado de la audiencia, lo cual resulta facilitado por los algoritmos que estudian a la audiencia.

De Maeyer (2009) sostiene que las redes sociales determinan efectos sobre las prácticas y las rutinas cotidianas del periodismo. Para constatar este criterio de manera empírica basta con acercarnos a una sala de redacción contemporánea donde Twitter, Facebook, WhatsApp, Youtube, Flickr y otros medios sociales son parte del entorno de trabajo de los periodistas. Si luego nos detenemosa revisar su producción notaremos de qué manera son utilizados estos recursos para la cobertura noticiosa desde el lugar de los hechos así como para la labor cotidiana en las salas de redacción. Sobre este particular Cerviño (2013) destaca el liderazgo del diario El País en el uso constante de citas directase indirectas de ciudadanos desconocidos quienes protagonizan un hecho concreto, y se expresan a través de las redes sociales, así como de comportamientos colectivos.

Thomas (2013) investiga en qué medida las redes sociales están influyendo y perfeccionando la profesión periodística. Su estudio cualitativo utilizó entrevistas directas, vía Skype y correo electrónico a 8 periodistas involucrados en la producción noticiosa. Se demuestra la influencia significativa de las redes sociales en la actividad periodística. La interactividad con la audiencia determinauna agilización de los procesos de producción noticiosa, el reforzamiento de las redes y la retroalimentación de la audiencia en tiempo real.

González-Molina y Ramos del Cano (2014) estudiaron en forma comparativa cómo se utilizan dos redessociales (Facebooky Twitter) por parte de 41 medios de comunicación de seis países europeos: España, Francia, Italia, Alemania, Finlandia y Gran Bretaña, incluyendo medios de los 4 tipos de soporte 
(prensa escrita, radio, televisión e internet) representativos de los tres modelos de medios de comunicación, el Pluralista Polarizadodel Mediterráneo (España, Francia e Italia);el Democrático Corporativo del Norte yCentro de Europa (Finlandia y Alemania); y el Liberal del Atlántico Norte (Gran Bretaña), clasificación efectuada por Hallin y Mancini (2008). Se concluyó Facebook y Twitter son las dos redes más importantes para los 4 tipos de soporte del periodismo, siendo la prensa escrita la que más claramente apostó por estas dos plataformas, en lugar de diversificar su presencia en un gran número de redes sociales. Su uso es marcadamente informativo El estudio de Gillis y Johnson (2015) demuestra que, en general, en los Estados Unidos se ha incrementado el uso de lasredes sociales entre los periodistas; y que los periodistas jóvenes son quienes está más motivados para utilizar las redes sociales. Esto lo hacen con tres propósitos: Obtener y desarrollar ideas para noticias, conectarse con las fuentes potenciales y difundir noticias.

Sánchez (2017), al estudiar sobre la construcción mediática de las redes sociales en los periódicos mexicanos, encontró quelos periódicos en línea crean una imagen superficial de las redes sociales y alejadasde su propia dinámica. La representación mediática de las redes sociales es parcialy sesgada. Se parte de los tradicionales valores periodísticos. Las redes sociales son construidas simbólicamente con base en los valores-noticia y rutinas productivas de los medios

Al referirse a los contenidos sensacionalistas originados en redes sociales que se divulgan en la televisión ecuatoriana, González (2016) señala que corresponden al interés de los medios de comunicación para ganar un mayor índice de audiencia Los criterios de selección de la información de las redes sociales que se transmiten en canales televisivos son el morbo y la inmediatez.

Yezers'ka (2012) analiza los recursos interactivos en 20 ediciones digitales de diarios peruanos. Diez diarios son de circulación nacional y diez regionales. Revela que las redes sociales son usadas por 7 de cada diez diarios. El 70 por ciento mantiene una cuenta en Facebook, el $65 \%$ en Twitter y el 15\% un canal en Youtube

\section{Conclusiones}

Actualmente, con la irrupción de las redes sociales y del periodismo digital dado desde esta última década, se tiene una vorágine de información al alcance del periodista, que es el profesional que con mayor pertinencia hace uso de las redes digitales. Se habla ahora de la construcción y análisis de bases de datos de fuentes y temas, como andamiaje y sustento de toda la investigación

Las redes sociales ya han entrado a los medios $y$, al hacerlo, progresivamente conduce a los medios a adecuarse a la dinámica del periodismo digital, incorporando la sinergia multimedia y la interactividad con idoneidad en tiempos reales. El reto actual es acercarse a la verdad en un contexto donde los mayores flujos de información elevan las demandas de análisis y síntesis, pero también en un contexto donde las fake news también invaden el ciberespacio. Para producir un periodismo de mayor calidadla capacitación es vital, para apropiarse, con rigurosa precisión y responsabilidad, de las herramientas tecnológicas, de los métodos y las técnicas que ahora la ciencia de datos provee.

\section{REFERENCIAS BIBLIOGRÁFICAS}

Bruns, A. (2008). Blogs, Wikipedia, second life, and beyond: From production to produsage.New York: Peter Lang.

Bunz, Mercedes (2010). "Most journalist use social media such as Twitter and Facebook as a source". The Guardian, 2010. [en línea] [Consulta: 07 febrero 2014]. <http://www. theguardian.com/media/pda/2010/feb/15/ journalists-social music-twitter-facebook>.

Butts, C. (2008) Social network analysis:A methodological introduction. En AsianJournal of Social Psychology, 11 (1), 13-41

Carrera Álvarez, Pilar, y otros (2012a). "Periodismo y Social Media: cómo están usando Twitter los periodistas españoles." Estudios sobre el mensaje periodístico, vol. 18, nº1, pp. 31-53. 
Carrera Álvarez, Pilar, y otros (2012b).“Quién soy yo y quién eres tú?" ¿Están transformando las redes sociales la imagen que los periodistas radiofónicos españoles tienen del público?". Estudios sobre el mensaje periodístico, 2012b, vol. 18, pp. 223-231.

Casero-Ripollés, Andreu; Feenstra, Ramón Andrés (2012). “The 15-M Movement and the new media: A case study of how new themes were introduced into Spanish political discourse". MIA. Media International Australia, 2012, nº144, pp. 68-76.

Cerviño, B. (2013) El uso de las redes sociales como fuentes de información para Periodistas (Tesis Maestría) Barcelona: Facultat de Ciències de la Comunicació, Universitat Autónoma de Barcelona

Chung, J. y Buhalis, D. (2008). "Information needs in online social networks". Information Technology \& Tourism, 2008, Vol. 10, (4), 267-281.

Colle, R. (2016) Sistémica de los mediosde comunicación en la era de las redes Santiago de Chile: INCOM Chile/ Asociación Chilena de Investigadores en Comunicación

De Maeyer, J. (2009). “Journalism practices in an online environment. An investigation into the evolving specificities of newswork in Belgium, as challenged by technological changes". http://juliettedm. files.wordpress.com/2010/04/journa lism_ practices.pdf

Flores, J. (2009) Nuevos modelos de comunicación, perfiles y tendencias en las redes sociales, Comunicar, XVII (33), 7381. DOI:10.3916/c33-2009-02-007

Fowler-Watt, K. y Allan, S. (2013) Journalism; New challenges, Dorset: Centre for Journalism \& Communication Research, Bournemouth University

Gillis, T. y Johnson, K. (2015) Younger journalists more likely to use social media, Newspaper Research Journal , 36(2), 184-196
González-Molina, S. y Ramos del Cano, F. (2014). “Redes sociales en el ámbito periodístico: ¿Cómo usan los medios europeos de referencia sus perfiles en twitter y facebook?". Revista interdisciplinar de Ciencias de la Comunicación y Humanidades de Comunicación y Hombre $\mathrm{N}^{\circ}$ 10, noviembre 2014. Universitat Jaume I Castellón. España. Recuperado de https://portalderevistas.ufv.es/index.php/ comunicacionyhombre/article/view/174/13

González, M. (2016) Contenidos sensacionalistas en redes sociales y su divulgación en la televisión ecuatoriana, caso: noticiero Pantalla Real, segmento insólito, del 1 de agosto al 1 de septiembre de 2016. Tesis para obtener el título de Licenciado en Comunicación Social. Facultad de Comunicación Social. Universidad Central del Ecuador. Disponible en http://www.dspace. uce.edu.ec/bitstream/25000/13048/1/TUCE-0009-039 2017.pdf

Hallin, Daniel y Mancini, Paolo (2008). Sistemas mediáticos comparados. Tres modelos de relación entre los medios de comunicación y la política.

Barcelona: Hacer Hootsuite Media Inc. (2017) Digital in 2017 Global Overview. Vancouver, Canada: Autor. Recuperado de https://www.slideshare.net/ wearesocialsg/digital-in-2017-globaloverview

Jaraba, G. (2017). “De qué conversan los periodistas españoles en Twitter". Departamento de Periodismo y Ciencias de la Comunicación. Universidad Autónoma de Barcelona. Disponible en https://gabrieljaraba.files.wordpress. com/2017/11/tesis-gabriel-jaraba definitiva.pdf

Lorenzo, C.; Alarcón, MC. y Gómez, MA. (2011). “Adopción de redes sociales virtuales: ampliación del modelo de aceptación tecnológica integrando confianza y riesgo percibido". Cuadernos de Economía y Dirección de la Empresa, 14 (3), 194-205. 
Masip,P.,Díaz-Noci, Domingo, D., Mikó-Sanz, J. y Salaverría, R. (2010) Investigación internacional sobre ciberperiodismo: hipertexto, interactividad, multimedia y convergencia". El profesional de la información, 2010, 19 (6), 568-576.

McDonald, A. (2013) The Impact of UserCreated Content on Traditional News (Thesis MA). College of Humanities and Social Sciences of Kennesaw State University, Georgia

Noguera, J (2012) "Redes y periodismo. Cuando las noticias se socializan". Barcelona: Editorial UOC.

Pérez, J. (2011). Twitter, los periodistas y las fuentes: del desierto a la selva.Recuperado de http://www.manualdeestilo.com/ herramienta/twitter-losperiodistas-y-lasfuentes-del-desierto-a-la-selva/

Phillips, A. (2011). "Faster and shallower: homogenization, cannibalization and the death of reporting". En Lee -Wright, P., Phillips, A., Witschge, T. (Eds.)Changing Journalism. Londres: Routledge, 2011, pp. 81-98.

Quiroz, Y. (2014). Las redes sociales como herramientas del periodismo digital social. Revista Cultura $N^{\circ} 28$. Facultad de Ciencias de la Comunicación, Turismo y Psicología. Universidad San Martín de Porres. Perú. Recuperado de http:// www.revistacultura.com.pe/imagenes/ pdf/28_10.pdf

Ramos del Cano, Fátima (2013). Redes sociales en el entorno radiofónico: el uso de Twitter como fuente periodística en la Cadena SER. Revista mediterránea de comunicación. Mediterranean journal of communication, vol. 4, no 2, pp. 173-188.

Russial, J., Laufer, P. y Wasko, J. (2015) Journalism in Crisis?, Javnost - The Public, 22 (4), 299-312 DOI:10.1080/13183222.2015 .1091618

Sánchez, J. (2017). La construcción mediática de las redes sociales en los periódicos mexicanos. Tesis Doctorado Ciencias dela Información, Madrid: Universidad Complutense

Thomas, C. (2013) The development of journalism in the face of social media: A study on social media's impact on a journalist's role, method and relationship to the audience, MA Thesis, Universityof Gothenburg Department of Applied Information Technology Gothenburg, Sweden.

Thurman, N. (2008) Forums for citizen journalists? Adoption of user generated content initiatives by online news media. New Media \& Society, 10(1), 139-157 http:// dx.doi.org/10.1177/1461444807085325

Toffler, A. (1980). The third wave. New York, NY: William Morrow

Yezers'ka, L. (2012). Gestión de los recursos interactivos en los ciberdiarios peruanos. Comunifé, 12, 13-32

Zambrano, José (2013) “Definición de Comunicación" (en línea). Disponible en: http://comunicacion-digital-jose.blogspot. com/2013/04/definicion-comunicacion digital.html (citado el 14 de noviembre del 2016). 